\title{
Teknik Analisis Naskah Berhuruf Arab
}

\section{Masyhudi}

Keywords: inscription, method, theory, practices, analysis

\section{How to Cite:}

Masyhudi, nfn. (2000). Teknik Analisis Naskah Berhuruf Arab. Berkala Arkeologi, 20(1), 47-53. https://doi.org/10.30883/jba.v20i1.806

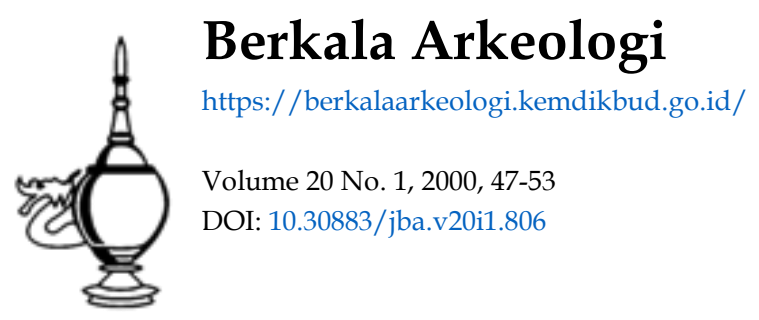

\section{c) (1)(2)}

This work is licensed under a Creative Commons Attribution-NonCommercial-ShareAlike 4.0 International License. 


\title{
TEKNIK ANALISIS NASKAH BERHURUF ARAB
}

\author{
Masyhudi \\ (Balai Arkeologi Yogyakarta)
}

\section{Pendahuluan}

Naskah (manuskrip) adalah semua jenis peninggalalan tertulis pada bidang kertas, daluwang kulit kayu, kulit binatang, lontar, bambu dan lain sebagainya yang dapat memberikan sumbangan bagi kebudayaan di Indonesia, karena pada umumnya naskah-naskah kuna merupakan suatu dokumen yang mengandung pikiran, perasaan dan pengetahuan dari suatu masyarakat atau kelompok sosial-budaya, sehingga naskah dapat dikatakan sebagai sumber primer untuk penulisan sejarah dan arkeologi di Indonesia (Boechari, 1975).

Penelitian naskah-naskah kuna pada umumnya bertujuan untuk mengungkap kebudayaan dalam arti luas, maksudnya dengan naskah-naskah yang telah dihasilkan dari suatu penelitian akan dapat terungkap persoalan-persoalan masyarakat pada kurun waktu tertentu, meliputi; tradisi (adat kebiasaan suatu masyarakat), pikiran kepercayaan, sistem nilai dan lain sebagainya yang semuanya untuk menghadapi dan menyesuaikan diri dengan situasi yang tumbuh dan berkembang, baik dalam kehidupan secara individu maupun dalam kehidupan kelompok, (Robson, 1978).

Pada kenyataan di lapangan dalam suatu penelitian, keberadaan data tekstual berupa naskah sangat sulit dilacak, hal ini disebabkan oleh beberapa hal, antara lain; sifat naskah yang moveable, yaitu mudah berpindah tangan dari pemilik asalnya, Kebanyakan para penili tidak mengetahui bahwa di suatu daerah tertentu terdapat naskah, sehingga keberadaan naskahnya luput dari pengamatan, Karena suatu naskah tidak boleh dilihat atau diteliti oleh siapapun, karena dikeramatkan, dan karena naskah merupakan barang warisan, sehingga keberadaannya dirahasiakan (Edi.S,Ekadjati, 1983).

Pengetahuan yang berhubungan dengan studi naskah atau studi yang berkaitan dengan latarbelakang kebudayaan yang didukung oleh naskah disebut dengan istilah filologi, maksudnya studi naskah merupakan suatu studi yang berupaya mengungkap hasil budaya suatu bangsa, melalui kajian pada suatu tinggalan dalam bentuk naskah (sumber tertulis).

Penelitian terhadap sumber tertulis berupa naskah, sering dilakukan, akan tetapi secara teknis beberapa penelitian yang dilakukan belum menampakkan suatu sistematika yang runtut. Hal yang demikian banyak terjadi pada saat proses penelitian mencapai 
pada tingkat analisis. Oleh karena itu makalah ini akan mencoba menyajikan suatu teknik analisis terhadap sumber tertulis berupa naskah, dan secara khusus akan dibatasi pada naskah yang berhuruf Arab. Hal ini dimaksudkan untuk dapat dijadikan pegangan pada saat penelitian, khususnya penelitian terhadap tinggalan-tinggalan tertulis, berupa naskah, sehingga suatu penelitian di masa-masa mendatang yang menjadikan naskah sebagai obyek, akan dapat lebih efektif dan lebih terarah.

\section{Analisis Naskah}

Pada dasarnya antara naskah dan teks terdapat perbedaan, yaitu naskah merupakan suatu benda yang konkrit (dapat dipegang), sedangkan teks merupakan coretancoretan yang terdapat di dalam naskah dalam bentuk tulisan, atau dengan kata lain teks adalah muatan atau bagian daripada naskah. Untuk mempermudah memahami pengertian tentang naskah berhuruf Arab yang dimaksud dalam tema sebagaimana tersebut di atas adalah teks dari naskah-naskah yang berhuruf Arab.

Sebagaimana lazimnya penelitian terhadap naskah-naskah kuna, sebelum melangkah kepada analisis terhadap bahan, alat, maupun teks naskah, terdapat beberapa hal yang harus diketahui lebih dahulu, yaitu tentang keberadaan naskah yang mencakup; nama situs, (dusun, desa/kelurahan, kecamatan, kabupaten, propinsi tempat diperoleh atau ditemukannya naskah). Kemudian kronologi perolehan naskah, yaitu meliputi tanggal, bulan dan tahun dilakukannya peneltian. Hal ini dimaksudkan untuk mengetahui kapan suatu naskah diperoleh atau ditemukan. Kalau suatu naskah yang diperoleh atau diteliti merupakan naskah yang sudah pernah di analisis, maka perlu dicantumkan nomor analisis. Kemudian perlu juga diketahui cara perolehan apakah suatu naskah diperoleh dengan cara survei atau koleksi, kalau diperoleh melalui koleksi, maka hendaklah dicantumkan nomor koleksi. Untuk mempermudah mengenal suatu naskah, maka perlu diketahui tentang judul naskah. Disamping itu juga perlu diketahui tentang asal-usul naskah, apakah suatu naskah diperoleh (dimiliki) dengan cara turun temunun, menyalin dan lain sebagainya. Selain itu perlu diketahui juga mengenai kondisi naskah, yaitu apakah naskah yang diteliti atau di temukan dalam kondisi masih utuh, tidak utuh, rusak, lapuk, aus dan lain sebagainya. Setelah dilakukan beberapa hal sebagaimana tersebut di atas, barulah melangkah kepada analisis naskah, baik yang menyangkut bahan, alat maupun teks naskah.

Analisis terhadap naskah, pada umunya dilakukan melalui suatu proses, di mana proses tersebut akan dapat berjalan secara efektif apabila dilakukan secara sistematis. Beberapa hal yang perlu diperhatikan dalam tahapan-tahapan analisis naskah adalah;

A. Kodikologi

Kodikologi adalah suatu pengetahuan tentang kode (buku-buku yang berupa manuskrip), dengan kata lain kodikologi merupakan suatu ilmu yang mempelajari 
tentang seluk-beluk naskah, secara fisik, baik berupa bahan-bahan yang digunakan, misalnya kertas, daluwang, lontar, bambu, kulit kayu, kulit binatang dan alat-alat yang digunakan untuk membuat naskah, misalnya pena tinta maupun terhadap muatan naskah berupa teks naskah, misalnya jenis aksara, jenis bahasa dan lain sebagainya.

\section{B. Translitrasi dan Transkripsi}

Translitrasi adalah pemindahan tulisan dari satu abjad atau huruf ke abjad yang lain, misalnya dari dari huruf Arab ke huruf latin. Sedangkan transkripsi hampir memiliki pengertian yang sama, yaitu pemindahan tulisan, akan tetapi masih tetap dalam huruf yang sama. Kedua istilah tersebut, dalam proses analisis naskah biasanya dipakai bersama-sama dan keduanya sama-sama penting untuk memperkenalkan teks-teks naskah. Khusus untuk naskah-naskah berhuruf Arab, terdapat beberapa hal yang perlu diperhatikan, yaitu;

1. Pengenalan dan pemahaman luruf Arab

Huruf-huruf Arab menurut ucapan dalam bahasa Arab, sebagaimana terhitung di dalam Al-Qur'an terdiri dari 28 (dua puluh delapan) huruf. Di dalam Bahasa Arab terdapat beberapa bunyi huruf yang tidak terdapat di dalam bahasa 'ajam (non Arab), dan juga sebaliknya, ada bunyi huruf-huruf non Arab, yang tidak terdapat di dalam bahasa Arab. Selain itu juga terdapat huruf-huruf yang dipakai di dalam bahasa Arab, namun tidak ada fungsi bagi bahasa lain, misalnya; Dza $(\dot{b})$ ), "Ain $(\mathcal{G})$, Shad $(\infty)$, Dhad $(\infty)$ dan Dzal ( $j$ ), tidak terdapat di dalam bahasa Persi. Bunyi huruf Tsa ( $\dot{ })$ tidak terdapat di dalam bahasa Persi dan Rumawi. Bunyi huruf $\mathrm{Fa}$ ( $)$ ) tidak dikenal di dalam bahasa Turki. Demikian halnya dengan bahasa Indonesia tidak terdapat bunyi huruf 'Ain ( $\&$ ) dan Dza ( $\dot{b})$, misalnya ( $\mu b)$ Dzahir menjadi lahir, (

Keterangan mengenai huruf arab yang berjumlah 28 (dua puluh delapan) buah adalah sesuai denga hadits nabi yang diriwayatkan oleh Abu Dzar yaitu 28 (duapuluh delapan) buah, tidak termasuk (Lam-alif), sedangkan hamzah termasuk Alif, sehingga jika hamzah dan lam alif dihitung, maka jumlahnya menjadi 30 (tiga puluh) buah. Huruf-huruf tersebut adalah;

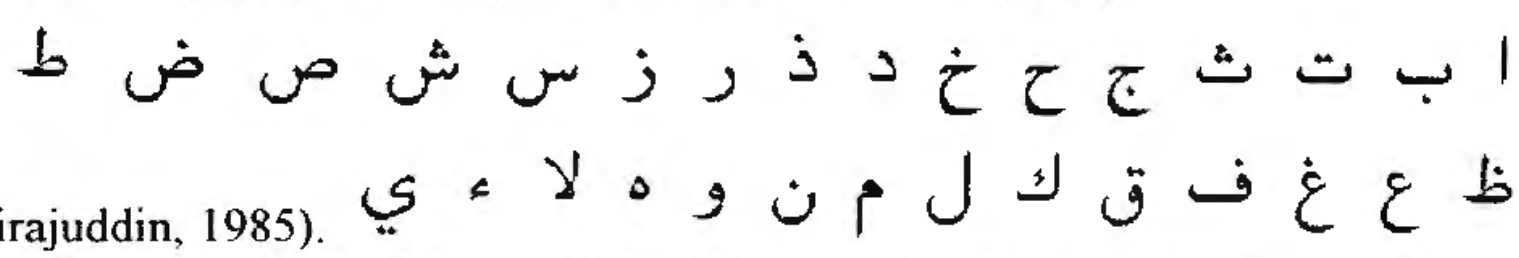

2. Pemahaman terhadap jenis huruf berhubungan dengan seni khat (kaligrafi).

Jenis-jenis huruf Arab yang sesuai dengan pedoman kaidah kaligrafi jumlahnya banyak sekali, diantara jenis-jenis huruf yang terkenal adalah Tsulutsi, Nskhi, Kufi, Diwani, Riq'i, Farisi dan Raihani.

3. Pemahaman terhadap kaidah-kaidah bahasa Arab. 
Untuk pemahaman terhadap bahasa Arab memerlukan beberapa ilmu bantu, yaitu ilmu-ilmu yang berbicara tentang kaidah-kaidah bahasa Arab. Ilmu-ilmu tersebut antara lain ; Nahwu, Sharaf (sintaksis dan morfologi, Badi', Ma'ani, Bayan (balaghah), Tajwid ( Fonologi) dan lain sebagainya.

4. Pemahaman dan penguasaan terhadap makna dan arti

Pemahaman dan penguasaan terhadap makna dan arti dari setiap lafal yang terdapat di dalam naskah akan sangat membantu untuk mengetahui muatan atau kandungan naskah.

Empat hal tersebut di atas, dapat menjdikan sebagai modal utama dalam penelitian sumber tertulis berupa naskah, dan secara khusus terhadap naskah-naskah yang berhuruf Arab.

\section{Perbandingan Teks (Komparasi)}

Yang dimaksud drngan perbandingan teks di sini adalah perbandingan antara teksteks yang terdapat di dalam naskah. Apabila terjadi sebuah teks naskah ditulis dalam beberapa naskah, maka perlu adanya suatu perbandingan. Hal ini dimaksudkan untuk menentukan mana naskah-naskah yang dapat dipertanggung jawabkan. Adapun langkah-langkah yang harus ditempuh yaitu;

1. Membaca dan menilai seluruh naskah yang ada. Jika terdapat suatu keterangan bahwa suatu teks merupakan salinan dari teks yang lain dan tidak menunjukkan kekhasan, maka teks tersebut dapat di eliminir atau disisihkan.

2. Memeriksa keaslian suatu teks yang akan diteliti (analisis), yaitu apakah ada bagian-bagian yang dihilangkan ataupun penambahan.

\section{Analisis Teks}

Analisis teks adalah suatu tahapan analisis terhadap teks-teks yang terdapat pada naskah yang menyangkut beberapa hal, antara lain analisis bahasa, latar belakang kebudayaan, ragam-hias dan lain sebagainya. Demikian halnya dengan naskahnaskah berhuruf Arab, adalah salah satu bagian dari analis teks yang terdapat pada naskah. Dalam ha-hal tertentu, memang terdapat beberapa perbedaan dengan naskah-naskah lain yang non Arab yang memerlukan suatu penempatan/ pembahasan khusus dalam hal analisis. Namun secara umum sebagaimana umumnya analisis terhadap naskah didahului dengan hal-hal yang bersifat umum, misalnya nama situs (dusun, desa, kecamatan, kabupaten, dan propinsi), cara perolehan dan lain sebagainya. Selain itu juga hal-hal yang bersifat morfologis, misalnya jumlah halaman, jumlahhalaman kosong, jumlah kurasan, jumlah halaman baris pada halaman pertama, jumlah halaman baris pada halaman terakhir, watermark (cap air), sebagai lambang perusahaan yang membuat atau memproduksi bahan (kertas) yang berfungsi untuk memperkirakan kronologi, misalnya kertas buatan Holland, England, Madrid, Paris, Italia dan lain-lain sebagaimana lazimnya penelitian terhadap teks-teks naskah yang lain. 


\section{Analisis Naskah Berhuruf Arab}

Naskah-naskah berhuruf Arab merupakan suatu kajian yang sangat kompleks, sehingga perlu adanya batasan-batasan yang jelas. Dalam hal ini naskah-naskah berhuruf arab dapat digolongkan dalam beberapa jenis, yaitu

\section{A. Jenis naskah berdasarkan huruf dan bahasa}

Dalam naskah-naskah berhuruf Arab, terdapat beberapa variasi, di mana suatu naskah berhuruf Arab dapat diterapkan berbagai bahasa, yaitu;

1. Huruf Arab dengan bahasa Arab

Jika suatu naskah yang ditulis dengan huruf Arab, kemudian bahasa yang digunakan adalah bahasa Arab, maka naskah tersebut termasuk jenis naskahArab.

2. Huruf Arab dengan bahasa Melayu

Jika suatu naskah ditulis dengan huruf Arab, sedangkan bahasa yang digunakan adalah bahasa Melayu, maka naskah tersebut disebut jenis naskah Jawi (Anonim, 1988).

3. Huruf Arab dengan bahasa lokal (Jawa)

Jika suatu naskah ditulis dengan huruf Arab, sedangkan bahasa yang digunakan adalah Jawa, maka naskah tersebut termasuk jenis naskah Pegon.

B. Jenis naskah berdasarkan muatan / kandungan

Berdasarkam muatan-muatan atau kandungan yang terdapat di dalam naskah, maka suatu naskah dapat dikelompokkan ke dalam beberapa jenis, yaitu;

1. Naskah agama

Yaitu naskah yang di dalamnya memuat tentang kutipan ayat-ayat Al-Qur'an, Al-Hadits, hukum Islam, tauhid (aqidah), fikih, dakwah, akhlak, tasawwuf, do'a-do'a, mantra dan lain-lain.

2. Naskah Historiografi

Yaitu naskah yang muatannya mengandung unsur sejarah, baik yang menyangkut, nama tokoh, silsilah, wawacan, babad, riwayat dan lain-lain.

3. Naskah Sastera Budaya

Jenis naskah ini merupakan jenis naskah yang memiliki kandungan tentang hal-hal yang berkaitan dengan sastera dan budaya, misalnya, masalah kebahasaan, yaitu nahwu (sintaksis), sharaf (morfologi), Tajwid (fonologi), natsr (prosa), syi'r (puisi, tembang) dan lain sebagainya.

Analisis terhadap naskah-naskah kuna berhuruf Arab, adalah merupakan suatu pekerjaan yang tidak mudah, alasan yang sangat mendasar adalah karena, Arab bukan merupakan bahasa sehari-hari. Akan tetapi jika dilakukan dengan bekal ilmu-ilmu pendukung yang memadahi, semuanya akan dapat teratasi. Demikian halnya penelitian terhadap naskah-naskah kuna berhuruf Arab di Indonesia telah 
menunjukkan selalu adanya upaya untuk meningkat, baik dalam hal metode maupun teknik penelitian, dan lebih khusus lagi dalam proses analisis yang betul-betul rumit. Upaya ini dimaksudkan semata-mata untuk kemudahan-kemudahan dalam proses penelitian, sehingga suatu penelitian akan dapat berjalan dengan semakin efektif dan efisien serta mencapai apa yang telah menjadi tujuan dan sasaran penelitian.

Secara teknis, analisis terhadap naskah-naskah kuna berhuruf Arab, hampir sama dengan analisis terhadap naskah-naskah yang lain (non Arab). Hanyasaja ada beberapa hal yang perlu diperhatikan, agar tidak terjadi suatu interpretasi yang keliru, misalnya saja dalam menentukan jenis huruf. Jenis huruf dalam naskah, baik naskah yang berhuruf Arab maupun non Arab tidak pernah ada istilah huruf Pegon. Sedangkan istilah pegon, pengertiannya adalah jenis teks atau tulisan yang terdiri dari huruf Arab dengan menggunakan bahasa Jawa/lokal (Anonim, 1988). Selain penentuan huruf, perlu juga diperhatikan tentang pengolompokan jenis naskah berdasarkan muatan atau isi yang terdapat di dalam naskah, hal ini dimaksudkan agar pengolompokan jenis-jenis naskah berdasarkan muatan yang ada dapat diketahui dengan jelas.

\section{Kesimpulan}

Analisis terhadap naskah berhuruf Arab adalah suatu proses penelitian yang memerlukan kecermatan dan kehati-hatian, untuk itu sangat diperlukan adanya dukungan dari berbagai disiplin ilmu untuk dapat membantu memecahkan persoalanpersoalan yang ada di dalam naskah. Sehingga apa yang telah menjadi tujuan dan sasaran penelitian benar-benar dapat tercapai.

Berkaitan dengan hal tersebut, tentunya dalam suatu penelitian perlu adanya suatu metode dan teknik yang betul-betul akurat dan jelas. Uraian di atas telah memberikan gambaran yang cukup jelas tentang teknis analisis terhadap sumber tertulis, berupa naskah dan lebih khusus lagi, kepada naskah berhuruf Arab. Dari uraian tersebut dapat disimpulkan, bahwa dalam analisis terhadap naskah-naskah kuna berhuruf Arab terdapat beberapa tahapan yang harus di lalui, hal ini dimaksudkan agar dapat mencapai hasil analisis yang benar-benar terarah. Disamping itu, secara khusus dalam proses analisis terhadap naskah-naskah berhuruf Arab terdapat hal-hal yang sangat perlu diperhatikan, diantaranya hal-hal yang brkaitan erat dengan huruf dan bahasa Arab, termasuk ilmu-ilmu pendukungnya. Hal tersebut dimaksudkan agar tidak terjadi kesalahan dalam penafsiran dan interpretasi, sehingga pada akhimya dapat memberikan suatu interpretasi yang jelas dan akurat. 


\section{KEPUSTAKAAN}

Anonim, 1988. Ensiklopedi Nasional Indonesia, Jilid I, Cipta Adi Pustaka, Jakarta.

Boechari, 1975. Manfaat Studi dan Bahasa Jawa Kuna Ditinjau dari Sejarah dan Arkeologi, Majalah Arkeologi, I, Jakarta.

Ekadjati, Edi.S, 1983. Naskah Sunda, Inventarisasi dan Pencatatan Lembaga Kebudayaan Universitas Padjadjaran-Toyota Foundation, Bandung.

Robson Stuart, 1978. Pengkajian Sastera-Sastera Indonesia, Dalam Bahasa dan Sastera IV, Jakarta.

Sirajuddin AR, 1985. Seni Kaligrafi Islam, Pustaka Panjimas. Jakarta. 